\title{
Numerical/Visual Elaboration of the Temporal Distance in Teaching Tense-Aspect Distinctions in English
}

\author{
Buğra Zengin ${ }^{1, *}$ \\ ${ }^{1}$ Department of English Language and Literature, Namık Kemal University, Turkey \\ ${ }^{*}$ Correspondence: Department of English Language and Literature, Faculty of Arts and Sciences, Namık Kemal \\ University, Namık Kemal Mahallesi, Kampüs Caddesi, Tekirdağ, Turkey
}

Tel: 90-282-250-0000. E-mail: bzengin@rocketmail.com

Received: June 26, 2013

Accepted: July 17, $2013 \quad$ Online Published: August 2, 2013

doi:10.5430/wjel.v3n3p1

URL: http://dx.doi.org/10.5430/wjel.v3n3p1

\begin{abstract}
Teaching the English tense-aspect system is a challenging problematic area in that its acquisition is a major source of error for English L2 learners at all levels, which signals the need for a central focus on establishing form-meaning connections. A wise strategy would be the application of deliberate simplification of the linguistic material only to rectify it at later stages. Therefore, this study aimed to explore the ways to benefit from the distance as a metaphorical link between the past and present for its facilitation effect on learning the present, past and present perfect tenses. The distance was elaborated numerically and visually but the elaboration was kept to be minimum. The links were created between the visual and numerical cues and the target forms through shared partial similarities to help associate the temporal meanings with the auxiliary forms of 'be' and 'do', and the inflection markers of '-ed' and -s.

In a nonequivalent comparison-group design, ANCOVA and Kruskas-Wallis revealed the experimental group's significantly better performance in tense-aspect distinctions as regards temporal meanings. The results have implications for both temporal and nontemporal meanings (e.g. temporal, social or psychological distances). Being visual and numerical, cues can be universally applied to diverse contexts.
\end{abstract}

Keywords: English tense-aspect system; verb conjugations; mnemonics; memory strategy

\section{Introduction}

Grammar holds a central place in language teaching; however, given the limited classroom time, some selection is needed as to what grammatical features to teach based on learners' errors (Ellis, 2006a). In teaching English as L2, it is the learners' consistent mislearning of the tenses that causes difficulty for many teachers (Aitken, 2002). Niemeier and Reif (2008) state clearly that the tense subsystem constitutes a major source of error even for advanced learners. Likewise, Ganem-Gutierrez and Harun (2011) underline this subsystem as a well-documented problematic area, even at the advanced proficiency levels. Making a similar point, Kennedy (2003, as cited in Niemeier \& Reif, 2008) states that many experienced teachers consider the verb use including tense, aspect and modality to be one of the major problems common to learners from many different backgrounds.

All these persistent difficulties common to diverse contexts of teaching and learning make it difficult to turn explicit knowledge into implicit knowledge (acquisition), which is the key to communication. Reid (2000, as cited in Hinkel, 2004 , p. 8) notes that "verb tense errors can be serious" often to the degree of interfering with communication. In a study modeling learner difficulty, Ellis (2006b) reports the difference between explicit and implicit knowledge to be a marked one; grammatical features tested includes many verbal inflections. According to VanPatten, Williams, and Rott (2004), the challenge in acquisition requires a central focus on establishing form-meaning connections; however, the need for this focus has been neglected in case of the tense-aspect system, the most researched of the important subsystems in interlanguage grammar. They add that continued examination in this direction will pay off in theory and application (e.g. the effects of instruction). 
There is hope that the research conducted so far can help work out solutions for establishing links between tense-aspect forms and both temporal and non-temporal meanings. In fact, the solutions for the temporal meanings can be designed in such a way that can be adapted conveniently to those for the non-temporal meanings. For instance, it is possible to make use of the distance as a metaphor, as expressed by Batstone (1995), who states that there is a metaphorical link between the broad temporal semantic and attitudinal meanings, in other words, tense can be metaphorically elaborated to signal both levels of meaning. However, the latter is very often signaled covertly, in a much more delicate (more context-sensitive) way than relatively explicit grammatical signaling of the former. The attitudinal meanings can be inferred not simply from grammar but by taking bearings on the discourse as a whole, which involves paying close attention to the interdependence between grammar and lexis (Batstone, 1995). Hence, the need for applying deliberate simplification of the target grammatical structures first and rectify them at later stages as Johnson (1996) suggests in his evaluation of what materials designers can do.

\section{Literature Review}

\subsection{Prevalence of the Challenge of the English Tense-Aspect System}

Importance and difficulties related to the English tense-aspect system are reported to exist in several countries. In other words, the significance of the problems associated with the learning of the tense is universally pervasive throughout the world. The following examples from Europe (Germany, France, Turkey) and Asia (India, China and Japan) indicate its prevalence especially considering the populations of some of them.

A great deal of importance is accorded to it in the German educational system its basic knowledge being the standard practice in student placement criteria. It also has a prominent place in "the grammar sections of German school curricula as well as in higher education language courses and in most other programs." Added to this is the tendency in most textbooks (and self-study pedagogical grammars) to "devote a great deal of attention to tense-aspect morphology and use" (Neimeier \& Reif, p. 328). Reflecting India's ESL context, Alamelu and Menon (2011, p. 55) state that acquisition of tenses, of all the grammar components, deserves the primary importance from school to tertiary level. Yet, they note, it is widely accepted by teachers that mastery of this crucial component presents the most complex and challenging difficulty.

In Turkey, millions of learners' problems with the acquisition of the English tenses persist beginning to consume the class time in elementary through secondary to university levels. Focus is on grammar in general and the pedagogical tenses in particular. Yet, the persistence of the problem has been voiced even at the level of ministry of education.

Comparing academic writings of nonnative students from various countries with those of native speakers, Hinkel (2004) highlights advanced students' difficulty with the conventionalized uses of tense, aspect and the passive voice in written academic discourse despite several years of second language learning and use. Her study reports the majority of these students avoiding "complex verb phrase constructions as passive voice, the perfective aspect, or predictive/hypothetical would" (p. 23). Using a likert scale (1-5), Scheffler's (2009) study probes the perceptions of Polish students of English at a college of modern languages, who rate the difficulty of tense and the perceived need for the intervention of instruction to be 3.5 (the highest) and 4.6 respectively. Shin (2009, p. 393) reports that students in a French immersion program in Canada fail to acquire such features as verb tense markings even after many years of study. According to Yang, Huang, and Lee (2000), one of the last areas to be fully acquired in China is tense, as demonstrated by university students' considerable number of errors despite previous instruction at primary and secondary schools for more than 13 years. They list some possible reasons for Chinese ESL learners' problems: L1 interference, complexity of forms, and the lexical aspect in the acquisition of English tense-aspect forms.

L1 interference should be neither underestimated nor overgeneralized. Neimeier and Reif (2008) underline the problem related to the aspect, especially in cases of L1s with different or no aspectual system. On the other hand, in Lee and Huang's (2004) study with Chinese students, L1 traces do not suggest a strong role. In Collins' (2007) study, French L1 learners' more frequent errors compared to those of Japanese learners suggest that the reason might be the French compound past form competing with the English past simple. On the other hand, Collins' (2007) view is that in general L2 learners make errors in tense and aspect, yet not necessarily due to L1 interference.

Not necessarily an interfering factor, L1 may be used for its similarities to L2. Brooks-Lewis (2009) reports her adult students' statements of having benefited from awareness of the cross-linguistic similarities through the incorporation of their first language. In Copland and Neokleous' (2011) study, teachers' underreporting their actual use of L1 may be justified for their students' affective needs or cognitive processes. 


\subsection{The Need for Explicit and Intensive Teaching}

Highlighting the considerable attention recently paid to the conceptual domain of temporal relations, Giacalone Ramat and Banfi (1990) underline the considerable variation in linguistic codification of temporal relations from language to language (from Chinese with no verb inflections to Italian with its rich inflectional verb morphology). However, late emergence of the acquisition of verb morphology is common, one of the reasons for which is the ready availability and sufficuency of adverbs of time as cues. Giacalone Ramat and Banfi (1990) quote the exact words of Bardwaj, Dietrich and Noyan (1988, as cited in Giacalone Ramat \& Banfi, 1990, p. 405) on the conclusion reached by the ESF (European Science Foundation). "The acquisition of temporal referentiality proceeds from implicit to lexical and from there to grammatical devices."

Suggesting the need for explicit teaching, the conclusion of Sato's longitudinal study is in line with several others in that it indicates that "inflected past tense verb forms are slow to develop for naturalistic learners." With time expressed either adverbially or through pragmatic inference from the discourse content, there is little communicative pressure for her subjects (naturalistic learners) to use these forms. The second possibility is reported to be low phonological salience, and the third is L1 influence (Sato, 1990, as cited in Mitchell \& Myles, 1998, p. 110). Sato's study with the two naturalistic learners who relied "other-than-morphological means to mark past tense reference" demonstrated the insufficiency of conversational interaction for the past tense markers of the regular verbs (1990, as cited in Salaberry, 2000, p. 57). Studying untutored adults from different L1 background at the level of basic variety of English, Dietrich, Klein and Noyau (1995) reveal that self-sufficiency with the ready availibility of adverbials of time can result in clear shortcomings that affect communicative efficiency. They underline the need for intensity rather than duration of interaction to counteract against the consequent slow acquisition processes and fosilization that can induce stimatization of the learners outsiders. Salaberry $(2000$, p. 57$)$ states that "analysis of data from studies based on adult natural learners do not show any extended use of verbal morphology as usually reported in the case of classroom learners", which suggests the benefits of classroom teaching. The high salience of temporal adverbs, usually accompanying tense inflections, makes them redundant (Ellis, 2004), leading "L2 learners to attend to them and to ignore the grammatical-tense verb morphomes", which is "a prime motivation for explicit instruction" (Ellis, 2002, p. 307).

Nevertheless, turning the explicit knowledge of tenses into the implicit is a challenge. Ellis (2006b) has administered a grammar battery test to international students learning English as an L2 with mixed proficiency levels. Examples of those grammatical features found to be harder to acquire as implicit knowledge are question tags, 3rd person singular $-\mathrm{s}$, regular past tense -ed, since/for distinction with present perfect (cf. Ellis 2006b). On the other hand, yes/no questions, unreal conditionals and ergative verbs have been found to be most difficult to acquire as both explicit and implicit knowledge (Ellis, 2006b). These findings indicate the need to prioritize and intensify the instruction of tense-aspect system in teaching English, especially rule based systems.

As Skehan (1998) emphasizes, rule based system is demanding compared to exemplar based system in terms of processing, which suggests the need to prioritize the former in teaching. As a specific example regarding past tense -ed in particular, Skehan quotes Ellis (1987, as cited in Skehan, 1998) as stating that the irregular past which has a lexical basis does not require online processing demands of the morphologically constructed regular past. Ellis (2006a) emphasizes the learners' difficulty with the internationalisation of rules with the third person singular $-\mathrm{s}$ as well. According to Ellis (2006b), contrary to its late acquisition, it is typical of the structural syllabuses to present it earlier compared to irregular past tense verb forms figuring much later (Ellis, 2006b).

Apart from cognitive difficulty, it is also possible to notice the frequency and utility of tense forms. These traditional factors of frequency and utility (invoked by Mackey, 1976, as cited in Ellis, 2006a) are more to do with the use of foreground tense forms. Schmitt (2000) presents frequency lists where it is possible to see tense markers ranking high among grammatical words, which demonstrate a tendency to be the most frequent words in English.

On the other hand, most of the problems are to do with misuse, semantically inconsistent use, of tenses. Neimeier and Reif (2008) emphasize that the problem of ill-formedness is far less than that of the contextually inappropriate use. According to Aitken (2002), an experienced teacher himself, despite their best efforts, English L2 learners misuse, misunderstand, and misapply this challenging grammar feature. With concept boundaries less visible compared to those in vocabulary, especially in case of L1 interference, it is more difficult to make distinctions between different tenses, more so in case of teachers failing to understand the nature of the tense taught. One inevitable source of hardship is to do with memory in that students "have a great many things to remember at once" (Aitken, 2002, p. 5). 


\subsection{Tense/Aspect in ELT Materials: from Sentence Grammar to Discourse Grammar}

Although conceding that errors need not necessarily be attributed to the materials used in EFL classrooms, Neimeier and Reif (2008), nevertheless, emphasize that analysis of materials can help us find some link between recurrent errors and potentially misleading explanations. Making evaluations about the German textbooks, they attribute German students' difficulties with some grammatical units to the neglect of meaning. Neimeier and Reif (2008, p. 331) suggest that "an integration of semantic-conceptual level into the pedagogical materials alongside wih morpho-syntactic rules and examples of contextualized use might be useful and even necessary for the learners' cognitive construction of the English tense-aspect system."

Hinkel (2004) suggests that meanings, functions and uses of tense-aspect features are not addressed in depth in texts for academic writing despite the need for intensive instruction. Studying primary school textbooks used in Hong Kong, Yang et al (2000) criticise the simplicity and dominance of very basic communication situations in Hong Kong textbooks. They argue that balance can be realised with the inclusion of difficult language features for the academic development Hong Kong students need in secondary and tertiary education. This suggests inclusion of academic content and raising the difficulty level of communicative content. Jordan (1997, as cited in Hinkel, 2004, p. 10) argues for the necessity of focused instruction for L2 academic writers on "regularities of tenses, aspects and the passive voice in formal academic writing."

Gabrielatos (2003) describes the system of twelve tenses adopted in ELT materials as a product of interactions between tense, grammatical aspect and modality (e.g. two tenses [present, past] and two aspects [perfect, progressive] interacting to realize eight of these). However, he considers the information provided as piecemeal, incorporating only a few exceptions and neglecting context sensitivity and subjectivity - reference time and view of the event), which results in learners' confusion. Emphasizing the multiplicity of functions of the English tense, Tyler and Evans (2001, p. 64) demonstrate that insightful presentation of the non-temporal uses associated with tense is a difficulty faced by language teachers and observed in classroom settings. Reflection of the problem in "course books and pedagogical grammars is to treat them as exceptions, or worse to ignore them altogether".

As regards the type of grammar to use as a basis for teaching, Ellis (2006a) draws attention to the ascendancy of "descriptive grammars that detail the form-meaning relationships of the language." In his opinion, a grammar reference should "present information not only about linguistic form but also about the semantic and discoursal meanings" (Ellis, 2006a, p. 87). Alamelu and Menon (2011) suggest that the learning of tense lacks the incorporation of discourse, which should enrich its teaching if communicative proficiency is aimed. Bolitho (2011) criticises its delay until students reach advanced level or confront with it in real communicative contexts, however concedes the difficulty of dealing with grammar in real connected discourse in textbooks and classroom settings. According to Bolitho (2011), teaching tenses can benefit from the convenient sentence level grammar as a pedagogical tool.

In McCarthy's (2001, p. 106) words, "in looking at isolated sentences it may be that a detached, referential meaning such as pastness might be the only plausible mental contextualization." However, meaning-in-interaction is not limited to semantic meaning (e.g. in English - ed forms of verbs denoting pastness). Items in context can have meanings that extend - even contradict or obscure - 'core semantic' meanings in text (both written and spoken). According to discourse grammarians, depending on the context a sentence such as 'I wanted to talk to you' may mean either a report of a past-time state of affairs, or as a present-time indirect/polite request. As a typical textual pattern of initial scene-setting, present perfect may be used to grab the reader's attention to the details of a hot-news event, which are normally reported in past tense (McCarthy, 2001).

McCarthy (2001) questions the strong version of either end of the continuum, and finds it necessary to ask whether it would be right to "take the language out of the messiness of real context and simply present it as a system to be learnt in the abstract and only later applied to situations of real communication" (p.49). Conceding the value of holistic focus on form once learners are ready for integrating grammar, Swan (2005, p. 394) argues that "this will often need to be preceded by discrete presentation and practice".

Azar (2006, p. 4) states that sentence-level teaching material can help students to start to see the systematic relationships between form, meaning, and use and prepare for "larger understandings of how these relationships work." Both contextualized and sentence-level materials "can and should be included in a well-balanced program of second language instruction." Niemeier and Reif (2008, p. 327) summarize the literature on problems of both predominantly structural syllabuses and solely communicative has been questioned in the linguistic and pedagogical literature of the last decades". Langacker (2008) attributes grammar's bad reputation to the pervasiveness of mechanical exercises, the learning of irregularities, and the memorization of seemingly endless paradigms through which it is often presented, and the lack of general interest inspired to its portrayal in linguistics "as a system of 
arbitrary forms based on abstract principles unrelated to other aspects of cognition or human behavior".

\subsection{Summary of Cognitive Grammar}

The teaching of grammatical structures can benefit from their conceptual basis of the cognitive linguistics. It is possible to design models which are consistent with work on applied cognitive linguistics. Founder of the cognitive grammar, a relatively new paradigm, Langacker $(2008$, p. 7$)$ states that this major theory "belongs to the wider movement known as cognitive linguistics which in turn is part of the functional tradition" and summarizes the conceptual basis for its in grammar.

Langacker (2000) considers grammar and meaning indissociable in that "grammar reduces to the structuring and symbolization of conceptual content" (p. 1) and lists cognitive abilities as the "inborn capacity for certain kinds of experience" such as "a notion of spatial extensionality in which spatial configurations can be manifested" (eg. We sense the passage of time), and the ability to establish relationships (p. 2). Finally fundamental to cognition are image schemas (Lakoff, 1987; Johnson, 1987: both as cited in Langacker, 2000, p. 3) and metaphor.

Language is all about meaning, which resides in conceptualization, a primary means of engaging both the real and constructed worlds as cognition is both embodied and contextually embedded subsuming "any kind of mental experience (sensory, motor, emotive, intellectual) as well as an apprehension of the context in all its dimensions (physical, psychological, social, cultural, discourse) (Langacker, 2005). Embodiment is a key tenet in that "concepts, including linguistic concepts, are grounded in experience (bodily/physical experience, or social/cultural experience) (Barcelona, 1997, p. 9). "For finite clauses in English, the primary grounding elements are "tense" and the modals (Langacker, 2000, p. 23).

Cognitive grammar's "most fundamental claim is that grammar is symbolic in nature" (Langacker, 2008, p. 5). Specifically, the basic tenet is that achieving a conceptual unification lexicon, morphology, and syntax form a continuum consisting solely of assembles of symbolic structures (constructions), which are pairings of a semantic structure and a phonological structure. An immediate consequence is that all grammatical constructs are meaningful (Langacker, 2005), that is, grammatical elements have meanings in their own rights (like vocabulary items). An integral part of cognition and a key to understanding it, "grammar allows us to construct and symbolize the more elaborate meanings of complex expressions (like phrases, clauses, and sentences)" (Langacker, 2008, pp. 3-4) and, due to their symbolic nature, "reducible to form-meaning pairings" (Langacker, 2008, p. 6).

"By and large, the elements traditionally ascribed to grammar tend to be quite schematic (semantically and/or phonologically), whereas those assigned to lexicon tend toward greater specificity." Phonologically specific and symbolically non-complex, grammatical morphemes are schematic semantically. The grammatical rules, "simply schematizations of symbolically complex expressions, or constructions" (constructional schemas), are schematic semantically and phonologically (Langacker, 2000, pp. 18-19).

Crucial for linguistic semantics is "our capacity to conceive and portray the same situation in alternate ways" (construal), dimensions of which include perspective and prominence (Langacker, 2006, p. 18). "Linguistic forms just activate meanings" and the activation with the same form is not necessarily experienced the same way in everyone. "meaning is a result of experience, both collective and individual" (Barcelona, 1997, p. 9). "One facet of perspective is the presumed vantage point from which a scene is apprehended." Another is local view (eg. imposed by the progressive form -rising) versus global one (the simple verb rises). The two kinds of prominence especially important for grammar are profiling and trajectory/landmark alignment. For instance, a verb profiles a process (a relationship scanned sequentially in its evolution through time), the semantic notions trajector and landmark taken by Langacker (2006, p. 19) "to be the conceptual basis for the grammatical notions subject and object."

Conceptualization is dynamic (Langacker, 2001a, as cited in Langacker, 2006, p. 19). "Also remarkable is the extent to which imaginative abilities come into play" (Langacker, 2008, p. 4). Imaginative capacities fundamental to conceptualization are metonymy, metaphor, blending, mental spaces, and fictivity (Langacker, 2006). Svalberg (1986) believes that grammar seems frustrating when perceived as a collection of unconnected, rather random rules. She reports that her model's overall view of the verb system systematically simplifies it for her students of different ages and levels appreciating it as explanation and memory aid.

The teaching of the English tense and aspect needs to raise awareness to establish connections between forms and meanings. According to Lakoff and Johnson (1981, p. 287), the founding fathers of conceptual metaphor, one of the major theories in cognitive linguistics compatible to cognitive grammar, we are not normally aware of our ordinary conceptual system due to the automaticity with which we think and act. "One way to find out is by looking at language" as communication is based on the same system. Primarily based on linguistic evidence, they have found 
that "most of our ordinary conceptual system is metaphorical" and have found a way to begin to identify the metaphors that structure our perceptions, thoughts and actions.

Use of distance as a metaphor can help mediate the tense-aspect distinctions in the temporal and non-temporal uses as can seen in Batstone (1995) and Tyler and Evans (2001). In line with the distance metaphor, the model introduced in this article argues for a minimal elaboration of this metaphor to strengthen the associations between the morphosyntactic structures and the meanings (temporal and nontemporal).

Langacker's (2006, p. 29) "central claim about the English present tense is simple and straightforward: It specifies that the profiled clausal process precisely coincides with the time of speaking." It is elaborated in Langacker's (2001) account of the English present in another publication of his as well. Despite acknowledging his lack of knowledge in how to teach, understanding of how it works, in his view, is most probably relevant to the pedagogical problems posed. Langacker (2001) argues for the necessity of elaborate mental constructions to mediate the non-transparent relation between linguistic expressions and the world. Despite the commonplace observations (non-present uses of the present tense), Langacker (2001) states clearly "that the English present tense does in fact locate the designated process at the time of speaking". The present tense morpheme imposes an immediate scope coinciding with it (time of speaking) in contrast to the past tense morpheme imposing an immediate scope located prior to the speech event (Langacker, 2001, p. 22). This image suggests a distance with present tense taking the front and past tense placed at the back.

Distance is the key element in Tyler and Evans' (2001) work for all concepts signalled by the tense. They state that primary or literal meaning of the English tense is temporal reference, nevertheless it may implicate or signal other non-temporal functions. Not literally spatial but elaborated in terms of the same experientially-based image content, "the concepts of time-reference, intimacy, salience, actuality and attenuation are conceptualized in terms of proximal-distal relations with respect to the experiencer" (p. 80).

\subsection{Signs in the Research Literature for Constructing a Model}

Long time accepted role of the applied linguist is to "involve a process of simplification of the linguistic information for pedagogic purposes" (Johnson, 1996, p. 110). Materials designers may apply deliberate simplification to aid proceduralization process only to rectify at a later stage with the introduction of some language awareness activities (Johnson, 1996). Assuming "the perspective and methodology of cognitive linguistics" it is possible to "facilitate language teaching by providing a systematic model of the links among the semantics of tense markers, which is to say between temporal and non-temporal meanings" (Tyler \& Evans, 2001, p. 66).

If tense-selection can be shown to have specific discourse functions, sentence grammars can concentrate on what they are designed to do best: describing the formal aspects of tense-formation. The specific functions like marking for politeness or formality, suggesting the degree of likelihood, expressing the degree of certainty, and the present relevance of past events can be formally treated at the level of discourse. It is also a suitable level to solve complications which sentence grammar may only draw attention to: lack of correspondence between tense and time reference, the reference to time made by many devices other than tense; problems over tense/aspect distinction (Stubbs, 1983, p. 26).

Hughes and McCarthy (1998, p. 263) emphasize the need for moving "from sentence-based grammar to the discourse level". They state that a discourse grammar can include "discourse paradigm (in contrast to traditional ones" and provide "solutions brought about by post facto rules that fail to generate appropriate choices, different distributions of forms in spoken and written texts, items that make little sense if dealt with in stand-alone sentences". According to McCarthy (2001, p. 105), items occuring in texts seem to "have meanings in context that extended greatly the 'core semantic' meaning, or which even contradicted or obscured those core meanings" (eg. use of was in what was the name?, to foreground institutional politeness and service connections instead of pastness).

It is possible to establish links between sentence and discourse grammars. Batsone (1995) suggests the possibility of using notional/attitudinal distinction in formulating relationships between grammar and discourse. Some element of the semantic notional meaning is given a particular but related attitudinal orientation and the two levels of meaning bear a very close conceptual relationship with each other (Batstone, 1995). Teachers can help learners benefit from this close conceptual relationship and can move away from the sentence-based grammar to the discourse level. Niemeier and Reif's (2008, p. 331) emphasize the importance of establishing the semantic concepts prior to, or simultaneous with, "the introduction of the morphosyntactic forms to help them develop a meaningful understanding of the English tense and aspect system".

Time-reference, "the primary meaning associtated with tense forms" and non-temporal notions are elaborated in 
terms of an analogous image content, spatial deixis, or specifically proximal-distal relations. Therefore, it is possible to suggest that "tense morphemes, which denote time-reference, can come to implicate and ultimately denote non-temporal meanings" (Tyler \& Evans, 2001, p. 80). "Through usage-based conventionalization, i.e. pragmatic strengthening, a conventional non-temporal meaning can become associated with a particular tense morpheme" (Niemeier \& Reif, 2008, pp. 65-66).

Although Bolitho (2011) criticises the delay of the introduction of discourse until students reach advanced level or confront with it in real communicative contexts, he concedes the difficulty of dealing with grammar in real connected discourse in textbooks and classroom settings. According to Bolitho (2011) teaching tenses can benefit from the convenient sentence level grammar as a pedagogical tool. Therefore, in line with Bolitho (2011) and McCarthy (2001), this article suggests starting with the sentence based grammar and move to the discourse level in later stages given the complex and dynamic nature of language learning.

\subsection{Problems in the Turkish Context}

Attemps should be made to solve the problems of tense-aspect teaching frustrating the communicative aims which, in many contexts of the world, are verbalised but not realized. Since this study has such an aim, it is also necessary to introduce examples of research and teaching activities in the Turkish context where this study has been conducted. Alptekin and Tatar $(2011$, p. 337) draw attention to possible discrepancies between teachers' beliefs and actual practices: "what teachers say is not always what they do in the classroom. What they express to a researcher is often what they think a modern teacher should be saying, but the reality is often something else altogether." Just as in Akbulut's study (2007: as cited in Alptekin and Tatar, 2011, p. 388), several teachers may be found to express their beliefs about the high value of communicative language teaching and learner centered classrooms. Yet they find themselves in the midst of logistical challenges of the classroom situations that demonstrate the difficulty with adherence to their beliefs.

It is the grammatical structures that are "the central organizing features of the curriculum (e.g. present $>$ progressive $>$ comparatives $>$ simple present tense $>$ past progressive tense)" reflected in the coursebooks and methodological guidelines prepared by the Turkish Ministry of National Education according to a structural syllabus. What learners are exposed to are both focus on formal features exercised mechanically and metalanguage of the teachers paying lip service to language functions. This fails to "create a meaningful language learning experience for the students" (Alptekin, Erçetin, \& Bayyurt, 2007, pp.5-6).

It is challenging to integrate communicative practices into such "predominantly teacher-centred contexts where students memorize vocabulary, do grammar drills and read dialogues without much concern for meaning" (Alptekin $\&$ Tatar, 2011, p. 332). The primary and secondary education in Turkey are characterized by teacher-centred and rote memorization-based instruction. Having been nurtured under these circumstances, Turkish university students can be expected to be the recipients of information, and only rarely ask their instructors questions (Özkan \& Kesen 2008, as cited in Alptekin and Tatar, 2011, p. 335). On the other hand, several academics attempt to foster learner autonomy viewing it "as a remedy to almost all the ills of traditional education" (Alptekin \& Tatar, 2011, p. 335).

Presenting some similarities to Lai's (2009) desciption of Taiwan, the test-oriented education system in Turkey mainly focuses on preparing for tests subsequent to primary and secondary education. In fact, this makes it difficult to adopt models where students can gain in terms of process as well as product, especially with respect to speaking and listening abilities. According to Swan's (2005, p. 378) suggestion, naturalistically based approaches may be particularly inappropriate to the instructional contexts of most of the world's language learners, where there is a powerful case for proactive teaching incorporating formal syllabuses, and form- and meaning-based approaches should be integrated. As in Lai's (2009) study, insufficient English language learning environments where English is seen as a foreign rather than second language provide few opportunities to use and practice English, and the only strategy adopted is rote learning. Turkey has a similar in these respects. In general, it is an EFL setting. The only strategy used by many students seems to be rote memorization. Therefore, it is very important to train students in learning and using a variety of more systematic strategies to make them independent and effective learners.

For instance, it is possible to benefit from the concept of a time line where numbers can be formulated as cues for form and function mappings. Starting with a sentence-level grammar, the numerical distance designed to simulate the temporal distance can at later stages be metaphorically elaborated for attitudinal meanings where the distance would be social or psychological. The universal nature of numbers and images potentially allows its applicability less dependent on L1. 


\subsection{Research Questions}

The challenge in the acquisition of the English tense-aspect system is valid, whether the auxiliary is 'be' or 'do'. VanPatten (2004) draws attention to learners' well known problem with the time-taking acquisition of do as a dummy auxiliary. Lee and Huang's (2004) study focuses on the acquisition of the English verb 'be' which Chinese ESL learners have been perceiving as a problematic issue for a long time and criticises the fact that studies specifically focusing on the interlanguage 'be' are few in number (p. 211). Niemeier et al. (2008, p. 331) argue that criticism "must be raised against approaches taken by the textbook grammars resulting in "the extensive memory load students are burdened with through the learning by heart of rules and exceptions."

Avoiding such an extensive memory load, this study aims to construct and test a model pairing forms and rules of the three pedagogical tenses (present, past and present perfect) with two numbers ( 1 and 2) and one image (H). The only additional elaboration is to do with the third person singular (pairing of $-\mathrm{s}$ with zero). The model has been designed to teach the present, past and present perfect tenses through a minimal elaboration of the metaphorical distance between the past and present tenses to provide cues encoding/decoding form-function mappings in tense-aspect structures with this limited number of numbers and images.

As a teacher who has designed the techniques in the model, the researcher aims to investigate its facilitation effect on the recall of the target forms (auxiliary forms of 'be' and 'do', and the inflection markers of '-ed' and $-\mathrm{s}$ ) to be associated with the temporal meaning intended. It is assumed that the use of the distance for temporal meanings can be converted to the distance for non-temporal meanings. The model is in line with the concept oriented approach to second language acquisition. According to Bardovi-Harlig (2007, p. 58), "a basic tenet of the concept oriented approach to second language acquisition is that adult learners of second or foreign languages have access to the full range of semantic concepts from their previous linguistic and cognitive experience."

\section{Material and Methods}

\subsection{Model}

The model uses both visuals (e.g. time line) and numbers for memory aid in novel ways. Use of numbers or visuals is seen in pedagogical grammars (type I, II, III conditionals and traditional time lines), or grammar literature (cf. Langacker, 2001 for visuals) and Tyler and Evan, 2001, where present tense morpheme is represented by zero/s or $0 / \mathrm{s}$ as the default verb marking, and visuals in traditional time lines for tenses). However, in this model, both numbers and visuals are used at the same time. Besides, the letters are seen as not only alphabetic codes but also letters-as-images or symbols. For a better reading of the model, the model is demonstrated with figure 1 and 2 and the appendix A as to the way it was used in the teaching context of the experimantal group of this study.

First the present and past tenses are encoded with numbers, followed by the encoding of the grammar forms used in the tenses. The model encodes and decodes tenses with numbers ' 1 ', and ' 2 '. Located spatially on the time line behind the present, past tense, is presented as the number two tense. The present tense at front is presented as the number one tense. Number 1 and number 2 each associates key part of the target grammar forms: the first letter.

It is the first letter that is foregrounded in the representation of the target grammar forms. The two categories of auxiliary/copula 'be' and 'do' are represented as ' $b$ ' and ' $d$ ' verbs respectively. The convenience of the first letter is also used to distinguish the target forms of auxiliary/copula be ('b' verbs: 'Am', 'Is', 'Are'; 'Was', 'Were') and auxiliary/copular do ('d' verbs: 'do'/,',does', did).

It is also the first letter that can be foregrounded to prevent the target forms within the same category. In order to prevent confusion of one form with another in the b verb category ('Is' with 'Was', or 'Are' with 'Were'), the numerical association of the first letter is used. The first letter of was/were, ' $W$ ' (pronounced as double $U$ and orthographically double V) associates number two/second. The letter 'I' (Is) associates number one in Roman numerical system and 'A' ('Am', 'Are') represents the concept of being the first or number one (first quality, best grade, or simply the first alphabetical code in the Roman numerical system). The problem of confusing conjugations of 'do' ('do' or 'does' with 'did') is solved with foregrounding the distribution of the letter 'd' in each conjugation: double 'd' in 'did', one 'd' in 'do' or 'does'.

As for the affirmative sentences, where auxiliary 'do' is not used except for emphasis, the model assumes the regular verb in question as ' $d$ ' verb (remember the classification of verbs as ' $b$ ' and ' $d$ ' verbs). Inflection of a main verb with the past tense marker '-ed' results in double 'd' (eg. 'walk' and 'walked' are represented as one 'd' and double 'd'). In other words, as for the contiguous, or simple forms as in I listened, I washed (regular past), etc., where the relation 
between subject and predicate is direct (not mediated by any auxiliaries), the regular past inflection '-ed' is assumed to take place as the second ' $d$ ' of 'did'. Therefore, the past (number two) takes double ' $d$ ', with one 'd' (regular ' $d$ ' verb) plus another $\mathrm{d}(-\mathrm{ed})$, whereas the present (number one) tense takes only one ' $\mathrm{d}$ '.

The component for perfect aspect foregrounds a visual aid, one universal visual form. As for the present perfect, the first letter comes into play again. A time line is visualised where two vertical lines representing past and present and a line across these bridging the distance between them. Highligting the bridge can help to see the analogy or resemblence of the visual to the head letter of present/perfect auxiliaries: ' $H$ '.

Verbs are categorized as present, past, past participle. Therefore, if we assigned numerical values to verbs it would be logical to categorize them as verb three. In Turkish context, the present, past, and past participle are numerically represented as verb one, verb two and verb three. Connecting this to the model, this practice can be pragmatically used for the present perfect as well: two (past) plus one (present) equals three for the past participle of the present perfect. Even though there may not be such terminology outside Turkey, this does not necessarily mean such an order may not be introduced at all. This way present, past and past participle of irregular verbs can be listed sequentially in a paragraph in formative tests to help students select the correct verb.

As for the third person marking "-s", number zero is used in the model to bring convenience for Turkish L1 learners of English. The third person pronoun in Turkish is gender-neutral ' $O$ ', which resembles zero ' 0 ', the Turkish equivalent of which is SIFIR, with its head letter ' $S$ ' associating ' $\mathrm{S}$ '. For use of English in teaching English, teachers could use formal contiguity between the third person singular $-\mathrm{S}$ and the /s/ sound in "cipher" and its voiced counterpart in "zero". Further, the meta-language terminology 'no gender neutrality' in the third person pronoun may be labeled numerically as zero gender neutrality. It can also be applied to languages with no use of third person subject (associating the concept of zero) or no (associating the concept of zero) inflection on verbs with the third person subjects.

Practising the model in the classrooms, it is also possible to use other Turkish cues. In order to distinguish ' $b$ verbs' from one another and 'd verbs', Turkish equivalents of first and head are 'birinci' and 'baş' respectively, both starting interestingly with ' $b$ '. For the conjugations of 'do' ( $d$ verbs), the distribution of ' $d$ ' according to the number of the tense was shown with the Turkish equivalent of the word 'distribution' (dağılım) as well; both starting with 'd'. Besides, the term is easy to learn as another word from the same family, 'distributor,' is a borrowed word in many L1s. The participants in the experimental group have been made aware of these analogies raising conciousness in this direction.

Using universal codes (visual and numerical), keeping them to the minimum and the simplicity, compactness and coherence in the presentation of inter and intraconnections is aimed to facilitate the transfer of the declarative knowledge about the target structures. When learners forget or misunderstand information about a target structure, it is beneficial to have declarative knowledge at the beginning. At later stages, the minimalist amount of cues helps retrieval.

Johnson (1996) argues for the use of declarative knowledge as a useful first step for the development of procedural knowledge to go back to. Lack of such a mechanism results in error fossilisation. According to Mitchel and Myles (1998), without a controlled process of analysis with declarative memory, verb conjugations will only be "recalled as a list of verb endings" (p. 94). However, declarative knowledge by nature is slow and high on already scarce channel capacity (using much of working memory) and it may also disappear (Johnson, 1996). These have relevance to designing a model to facilitate teaching. The systematicacity in the nature of the model is an advantage to turn the declarative knowledge into the procedural, and prevents disappearance. (See Appendix A for some information on its application, Figure 1 for the visual, and Figure 2 for third person -S).

\subsection{Statistical Procedures Adopted}

In a nonequivalent comparison-group design, ANCOVA and Kruskas-Wallis were used to find out whether or not there was any significant difference between the groups' correct use of proper tense-aspect marking at the pretest and the three posttests preferring to control for the pre-test scores as the covariate (remove the preexisting differences). The students were post-tested three times with quizzes as part of a formative process of evaluation. Special care was taken to include test items similar in complexity and difficulty of forms.

Prior to the administration of the first and third tests, students were informed of the exam dates. However, in the second posttest, they were not informed that they would take a test in order to assess the retention of the target forms in case of no preparation. In the ANCOVA of the third test, the Levene F Statistic did not indicate equality of error variances (homogeneity of variances), so its non-parametric equivalent, Kruskas-Wallis test was preferred. Dörnyei 
(2007) states that in ANCOVA, if comparisons result in significant differences, those are related to events having taken place after the pretest. According to Kinnear and Gray (2006), when the The Levene F Statistic does not indicate equality of error variances (homogeneity of variances), the non-parametric equivalent of ANOVA (or ANCOVA), Kruskas-Wallis test is used.

\subsection{Participants}

The participants of the study were 62 first year students (aged 17-19) some of whom were the students of section A and the others section $\mathrm{B}$ of the Turkish language teaching department. The distribution is determined by the department before teachers are assigned to these sections. Section A and B take classes in different classrooms/schedules of the same department at the faculty of education of a university in Turkey. One was chosen as the control group, the other the experimental numbering 32 and 30 respectively. The former included nine females whereas there were thirteen females in the latter.

Almost all of them had failed the English language exemption test administered by the school of foreign languages of the same university. With vocabulary, grammar and reading sections, the test only assessed reading comprehension and did not include sections that assessed writing, listening and speaking skills. Those scoring below a certain threshold determined by the school had the obligation to take English lessons. Therefore, most students in both groups were assumed to be beginning level learners. Being few in number (at most three in each group), the exceptions who were graduates of high schools offering a year of English preparation where English was intensively taught.

All the students had three hours of English per week. The course provided a potential better than a two hour course with its potential to increase the grade point average. Besides this opportunity, the significance of English for employment prospects and the willingness to learn it to communicate with foreigners were enough reasons for many students to demonsrate adequate attention.

\subsection{Instruments}

The treatment group was introduced to the model by the teacher drawing it on the board step-by-step along with brief verbal explanations during the teaching activity. Brief summaries followed up in subsequent lessons. Repetitive feedback was provided during the practice activities. No printed textual or graphical information was given to the experimental group students to prevent the control group having access to the model.

Discrete point testing was used to exclude the variables other than the focus of the study. Aiming to assess the appropriate use of tense-aspect morphology, the discrete point tests were prepared, administered and assessed by the author, himself the teacher of the classes compared. Focusing on subcomponents of grammar or vocabulary, these tests are easy to prepare, administer, mark and evaluate by many teachers. They do not assess proficiency for naturalistic use of English; however, they can be prepared easily even if the teacher is inexperienced and used for formative purposes along with proficiency tests.

Each test included 25 items, which were sentences with gaps to fill in in twenty minutes time with the appropriate tense-aspect forms that they can choose from a list placed in a random order at the top of the exam paper. Care was taken to include equal number of questions for the target tenses. For instance, if 5 questions were reserved for present tense, the questions reserved for other tenses were more or less similar in number, but the students were not informed of this feature, i.e. equal number of questions, to prevent use of this knowledge as an extra advantage.

As a cue to distinguish between varieties of pedagogical tenses, translation equivalents into Turkish and adverbs of time were available. The teacher used mainly a literal approach to translation. Where necessary, brief notes in parentheses were added to help infer the meanings intended. To distinguish the progressive aspect, (be) in paranthesis was added along with the main verb. They were tested at their lesson hours. Here are some examples (also a sample of a whole exam is in Appendix B):

Ayten's friend ---------- (be) (drink) tea with us yesterday afternoon. (Ayten'in arkadaşı dün öğleden sonra bizimle çay içiyordu.) [response: was drinking]

One of them ---------- (work) with us since 2004. (Onlardan biri 2004'ten günümüze kadar bizimle birlikte çalışmıştır.) [response: has worked]

I ---------- (paint) the walls. (Emphasizing the relevance of the action seen at the time of speaking) [response: have painted] 


\subsection{Procedure}

First, all the students were informed of the importance of meanings behind the grammar forms reflecting them. They were instructed that the choice of which tense to use depends on the meaning intended, the functions aimed, the point made, the attitude shown, or the focus given. Therefore they learned that use of grammar is about meaning con by the speaker.

Grammar forms were presented in tables. Contrastive analysis and translation were also used. The rules were explained briefly in Turkish. Feedback was provided on error (metalinguistic explanations, feedback on error, contrastive analysis and translation). L1 was not excluded considering the benefits of contrastive analysis and traslation, the benefits of using a metalinguistic advantage and considering it as a tool to build on prior learning and to fill in the vocabulary gaps frequently occring at the beginning level. The teaching was gradually contextualised to the degree of paragraphs (sentences, short dialogues and other texts).

The treatments in both groups were mainly presentation, practice and production method. Grammar teaching was intensive with opportunities for repeated practice; the main difference in the experimental group was the integration of the model. The compact and pragmatic nature of the model allowed the teacher to present the present and past tenses at the same time at the beginning immediately followed by the present perfect (and its progressive aspect) later on in the subsequent lessons. In the control group, the students were taught discrete linguistic structures in separate lessons in a sequence of traditional course books.

\section{Results}

Prior to the present study, the model had been tested in two pilot studies conducted in consecutive years in the same faculty (faculty of education) of the same university, where the author (teacher/researcher) taught. The model raised the performance of students in their attempts to make distinctions with regard to the English tense-aspect markers. However, the students compared were from different departments and the number of students was either low or demonstrated inter-department differences (eg. religion culture and moral knowledge department compared to geography teaching with 32 and 20 students respectively, (In appendix C, tables are provided for the analysis of the pilot tests).

Following the encouraging results of the pilot tests during which the teacher also had more experience with the application, the model was tested in the Department of Turkish Language teaching, students of which had been registered to two separate classes by the administration of the department before the teaching activities started. Administered to assess prior knowledge, the pretest indicated no statistically significant difference, which suggested inter-group comparability. Most of the scores were quite low. This indicated that the students did not display any retention of the target grammatical forms they were supposed to learn.

The first posttest was administered after a six-week instruction. On average, the control group took 41.25 points. Not even half of the questions were answered correctly even though the test was informed. The experimental group outperformed the control group statistically significantly with a mean of 66.13. Many of the students responded more than half of the questions correctly.

The second posttest was administered two weeks later without informing the students beforehand of a test to be taken to compare the groups when they did not study for any test. The control group performed the poorest compared to all the other posttests with a mean a little below one third of the whole score, whereas the treatment group doubled that mean, still significantly ahead. This can be interpreted to reflect the effect of the standard condition to fall short of long term memory. The difference was lower compared with the first posttest but still the control group was significantly behind.

About three months into the term, they were tested for the third time. The test date was announced previous to its administration. The students' levels of recall of the target temporal forms were statistically significantly higher in the experimental group who correctly responded four fifths of the questions. The pre-post test difference at the second post-test was much higher than that at the second post-test. The average inter-group difference was just over 24 points (for details, see Table 1, 2, and 3).

\section{Discussions and Conclusions}

It can be inferred from the significantly higher scores of the experimental group that the memory techniques in the model can help, though indirectly, speed up the students' progress on mastering and establishing the form-meaning 
associations in terms of temporal meanings. The systematical and pragmatic use of the minimum number of numerical/visual forms can easily be used in intensive grammar teaching. Enhanced recall can motivate and facilitate the learners.

To sum up, we can infer from the SPSS results that the experimental group taught with the model demonstrated considerably better performance of constructing temporal form-function relations and outscored the control group in the three posttests with a statistically significant difference every time both groups were assessed. The two pilot studies and three posttests increased the reliability of the study. Hawthorne effect was avoided or prevented with the participants not being informed of the experiment. The statistical level in the ANCOVA and Kruskas-Wallis tests indicated the replicability of the study; however effect size was small for generalization. On the other hand, the findings have an ecological validity with the study conducted in real classrooms, which implies that practicing teachers can make use of the model. The participation was limited to beginner level adults in a university setting with Turkish used as the L1. However, the model can be applied in diverse contexts with participants speaking L1s other than Turkish due to the universal nature of numbers and images. It would be interesting to see the possible influences or effects of the model in experiments conducted in several contexts. The study is important in that acquisition of the tense aspect system is demanding as Bardovi-Harlig (1997, p. 375) emphasizes that "adding a new inflection in the tense/aspect system requires not only establishing new form-meaning associations but also revising existing ones."

The model has a teoretical depth given the relevant literature presenting an overview of cognitive grammar with which it is consistent. The study is original in that it applies the concepts of cognitive grammar to teaching focusing temporal meanings exclusively. As the groups compared were begininning-level students, the grammar taught was at the sentence level, which was limited to semantic notional meanings of the target pedagogical tenses (present, past, present perfect) of the English language. The level of the students was not considered to be suitable for discourse grammar which was therefore left out of the scope of the study. The assumption is that both temporal meanings share spatial relations analogous to non-temporal meanings, as can be seen in the explanations offered by Tyler and Evans (2001) and Batstone (1995). Application of these explanations in discourse grammar teaching activities should be tested in future studies.

As Prabhu (1995, p. 61) states, it is "difficult to establish one-to-one correspondence, on rational or commonsensical grounds, between specific types of classroom activity and specific concepts of what learning they promote" and various interpretations can be made of the effect of a particular teaching activity. Likewise, the inter-group difference in favor of the experimental group in terms of the test scores can be variously thought of as caused directly, facilitated or stimulated by the model, especially in terms of practice or explicit attention. To borrow Prabhu's (1995, pp. 61-62) words, it is difficult to state objectively whether the practice with it "established the target forms as behavioral habit", or "facilitating a process of rule abstraction by the learner." It is not directly clear whether the end result was "a mental representation of those rules as competence", "a store of such rules in memory for exclusive use in self-correction", or "a general condition of rule awareness which facilitates the learner's perception/re-creation of other, unspecified, rules" (pp. 61-62). Surveys should have been conducted to obtain the participants' evaluation of the process.

Aiming to teach the target forms, rules and the meanings behind them, and establish the temporal form-function relations so as to facilitate, bypass or speed up the process of tense aspect acquisition, the model was designed to simulate the numerical/visual elaboration of the distance through minimalist amount of numbers and letters-as-images the use of which corresponds to the first letters of $b$ and $d$ verbs and the distribution of the letter ' $d$ ' in ' $d$ ' verbs in a numerically elaborated time-line (plus a numerically and visually elaborated correlation between the third person $-\mathrm{s}$ and zero) in a way more systematic than rote-memorization. It is necessary not only to understand through a representation of rules but also use correct forms to reflect the meaning intended, especially in terms of accuracy in productive skills. Bidirectionality of associations between alphabetical codes and tenses to their numerical representatives allows the learner to translate from linguistic to numerically elaborated letters-as-images and vice versa. The model uses the overlap in mutual meanings which human intelligence can assign to or infer from linguistic forms, numerical and visual forms of thinking. This correlation between forms can help students of English to make tense-aspect distinctions in English significantly. The overall aim of the numerical and visual metaphors created was to raise awareness of the form-meaning mappings and mediate them to the students. Villamil and de Guerrero (2005) state that metaphor is the chief mediator of understanding.

On the other hand, the model does not include an in-depth explanation of the progressive aspect (See excellent ideas for progressive in Neimeier and Reif, 2008). That the progressive is an elusive concept for most learners is "still valid today" (Neimeier and Reif, 2008, p. 326). The progressive and non-progressive are labeled as one tense for 
convenience. In terms of testing, this limitation did not prevent the test taker to distinguish both aspects since 'be' was provided inserted in parenthesis with the main verb as a cue for the requirement of the progressive. Relevant for this issue is what Langacker (2006) explains as the vantage point, a facet of perspective, which is a dimension of construal, a fundamental claim of the cognitive grammar. Future experimental studies can apply this concept.

The teacher's feel for learning is important (Prabhu, 1995). As an experienced teacher who has interacted with the students, enjoyed the immediate student feedback, and made observations of their reactions over long periods of time, I believe that these applications should be encouraged and will pay off. Assumed to potentially make the instruction and revision more efficient and practical, the model might be considered to achieve what Neimeier et al. (2008, p. 326) consider necessary: the development of "meaningful understanding of the concepts underlying grammatical constructions" and "integration into communicative language learning environments". Compactness and economy of a teaching technique bring about efficiency and convenience for use in intensive grammar teaching, which can, according to Ellis (2006a, p. 94), help learners to progress through the sequence of stages involved in the acquisition of some structures, which may not occur "without opportunity for repeated practice".

Although instructional activities in control and experimental classes are mainly of a focus-on-forms kind, the model can be adapted to focus on form, (or integrated to use of text). Cumulated ample evidence indicates the general agreement on the need for some formal or concious attention to form (Burgess and Etherington, 2006; Borg and Burns, 2008). This is important in that Ellis' (2002, p. 223) review of previous studies suggests that form-focused instruction (FFI) "can contribute to the acquisition of implicit knowledge". Likewise, Spada and Lightbown (2008) highlight the increasing consensus on the benefit of FFI for features of the language that learners may not acquire without guidance. Lightbown and Spada (2006) underline its benefit for classes sharing the same L1 in making more efficient use of the limited L2 exposure.

All learners shared the same L1 and the teacher had the advantage of being their teacher who designed the model. The model has effective features worth trying out in the classroom. Minimalist use of the codes, all part of the shared knowledge (visual and numerical), in a simple logic provides economy for mental resources, and may constitute a model where different learning styles meet. More practical and faster reviews or summaries and the quicker access to the target grammatical structures facilitate teaching. Learners' cognitive resources are freed up so that teachers can increase communicative quality and content of the syllabus.

The model facilitates working with images. Arnold (1999) states that the process of forming mental images (visualization), although often unconscious, can be guided and partially domesticated; translation from meaning to images is direct as well. With the imagist approach to inferential thought patterns, Ralph Ellis (1995) underlines the significant influence of images as thinking is based on combination of sensory or sensorimotor images in different modalities and patterns.

The teacher should guide learners in looking to things in different perspectives. There is something artistic about it. Lanham's (2006) statement about arts is of relevance: "Last century abounded in visual exhortation to consider letters as images rather than alphabetic code, to look at them rather than through them" (p. 93). Highbee (1994) states that imagery mnemonics improves the cognitive effectiveness of recall, accommodating motivational potential with easier and more enjoyable learning. Besides, the features of Turkish language made it possible to use extra analogies both visual and auditory (analogy between the third person in Turkish [O] and zero [0] and curly feature of S). Rhyming effect produced was also humorous (O sifir oraya S'yi kıvır) but it is difficult to translate into English with the same effect. The analogy of curliness can be classified as using physical response and sensation. The conduct of the treatment as a whole included items from Puchta's (2010) list on what helps us to remember information: synaesthesis, movement, association, exaggeration, numbering/ordering/sequencing, symbolism, color, and, positivity. Elements of surprise in discovering are helpful (Puchta, 2006).

The results justify the candidacy of the model for a place in ELT teaching. The model can be introduced to those involved in teacher education programs as well. Once taught how to use, it can also increase the autonomy of the learner with its practicality. However, there have been some difficulties in the application of the model in the classroom. Having studied the tense-aspect system in the traditional way in their prior learning, the students were unfamiliar with the concepts, which they were asked to think about in a radically different way. The likelihood of obstacles standing in the way of applications of the cognitive grammar is acknowledged by Tyler (2012, p. 128: as cited in Higby, 2012, para. 12), who suggests the need for more time in the application of the approach, which "tries to give a more systematic way of learning certain grammatical constructions" (modals, prepositional structures, and dative alternation) besides rote memorization (para. 9). Having led a workshop to present the ideas to her teaching staff at a private ESL institute, Higby (2012) received positive feedback related to the modals voicing the need for 
the emergence of a grammar text offering "a full description and some focused student practice" to facilitate any implementation in their own classrooms (para. 11). Two of these teachers presented the concepts offered for modals to their students who "seemed to understand, but not apply them with confidence." Therefore teachers should teach with a large set of examples and patience with students who do not conceive the ideas right away (para 12) and insist on repetition to allow the novel information to sink in (para 9).

\section{References}

Aitken, R. (2002). Teaching tenses: Ideas for presenting and practising tenses in English. Walton-on-Thames: Thomas Nelson and Sons.

Alamelu, C., \& Menon, S. U. (2011). A form-focused activity to enhance acquisition of tenses. Language in India, Vol. 11, 54-61.

Alptekin, C., \& Tatar, S. (2011). A country in focus. Research on foreign language teaching and learning in Turkey (2005-2009). Language Teaching, 44(3), 328-353. http://dx.doi.org/10.1017/S026144481100005X

Alptekin, C., Erçetin, G., \& Bayyurt, Y. (2007). The effectiveness of a theme-based syllabus for young L2 learners. Journal of Multilingual and Multicultural Development, 28(1), 1-17. http://dx.doi.org/10.2167/jmmd470.1

Arnold, J. (1999). Visualization: language learning with the mind's eye. In Jane, A. (Ed.), Affect in Language Learning (pp. 260-278). Cambridge: Cambridge University Press.

Azar, B. (March 2006). Understanding and using English grammar: Interactive. TESL-EJ, 9(4).

Barcelona, A. (1997). Cognitive linguistics: A usable approach. In A. Barelona (Ed.), Cuadernos de Filologia Inglesa, 6(2), 7-32.

Bardovi-Harlig, K. (1997). Another piece of the puzzle: The emergence of the present perfect. Language Learning, $47(3), 375-422$.

Bardovi-Harlig, K. (2007). One functional approach to second language acquisition: The concept-oriented approach. In B. VanPatten \& J. Williams (Eds.), Theories in second language acquisition: an introduction (pp. 57-75). Mahwah, NJ: Lawrence Erlbaum.

Batstone, R. (1995). Grammar in discourse: Attitude and deniability. In G. Cook \& B. Seidlhofer (Eds.), Principle \& practice in applied linguistics (pp. 197-213). Oxford: Oxford University Press.

Bolitho, R. (2011). Holistic grammar teaching. English Teaching Professional, 75, 12-14.

Borg, S., \& Burns, A. (2008). Integrating grammar in adult TESOL classrooms. Applied Linguistics, 29(3), 456-482. http://dx.doi.org/10.1093/applin/amn020

Brooks-Lewis, K. A. (2009). Adult learners' perceptions of the incorporation of their L1 in foreign language teaching and learning. Applied Linguistics, 30(2), 216-235. http://dx.doi.org/10.1093/applin/amn051

Burgess, J., \& Etherington, S. (2002). Focus on grammatical form: Explicit or implicit? System, 30, 433-458.

Collins, L. (2007). L1 differences and L2 similarities: Teaching verb tenses in English. ELT Journal, 61(4), 295-303. http://dx.doi.org/10.1093/elt/ccm048

Copland, F., \& Neokleous, G. (2011). L1 to teach L2: Complexities and contradictions. ELT Journal, 65(3), 270-280.

Dietrich, R., Wolfgang, K., \& Colette, N. (1995). The acquisition of temporality in a second language. Amsterdam, the Netherlands: John Benjamins Publishing Company.

Dörnyei, Z. (2007). Research methods in applied linguistics. Oxford: Oxford University Press.

Ellis, N. (2002). Reflections on frequency effects in language processing. SSLA, 24, 297-339. http://dx.doi.org/10.1017.S0272263102002140

Ellis, N. (2004). The processes of second language acquisition. In B. VanPatten, J. Williams, S. Rott, \& M. Overstreet (Eds.), Form-Meaning Connections in Second Language Acquisition (pp. 49-76). Mahwah, NJ: Lawrence Erlbaum Associates.

Ellis, R. (2002). Does form-focused instruction affect the acquisition of implicit knowledge? Studies in Second Language Acquisition, 24(2), 223-236. 
Ellis, R. (2006a). Current issues in the teaching of grammar: An SLA perspective. TESOL Quarterly, 40(1), 83-107.

Ellis, R. (2006b). Modelling learning difficulty and second language proficiency: The differential contributions of implicit and explicit knowledge. Applied Linguistics, 27(3), 431-463. http://dx.doi.org/10.1093/applin/aml022

Ellis, R. D. (1995). The imagist approach to inferential thought patterns: The crucal role of rhythm pattern recognition. Pragmatics and Cognition, 3(1), 75-109. http://dx.doi.org/10.1075/pc.3.1.07ell

Gabrieletos, C. (2003). Teaching the expression of time: A concise framework. $37^{\text {th }}$ International Annual IATEFL Conference, Brighton Conference Centre, UK, 22-26 April, 2003.

Ganem-Gutierrez, G. A., \& Harun, H. (2011). Verbalisation as a meditational tool for understanding tense-aspect marking in English: An application of concept-based instruction. Language Awareness, 20(2). 99-119.

Giacalone Ramat, A., \& Banfi, E. (1990). The acquisition of temporality: a second language perspective. Folia Linguistica, 25(3-4), 405-428.

Highbee, K. H. (1994). More motivational aspects of imagery mnemonic. Applied Cognitive Psychology, 8(1), 1-12. http://dx.doi.org/10.1002/acp.2350080102

Higby, E. (2012). Book Review: Cognitive Linguistics and Second Language Learning: Tyler (2012). LINGUIST List, 23, 1915

Hinkel, E. (2004). Tense, aspect and the passive voice in L1 and L2 academic texts. Language Teaching Research, 8(1), 5-29. http://dx.doi.org/10.1191/1362168804lr132oa

Johnson, K. (1996). Language teaching and skill learning. Oxford: Blackwell Publishers Limited.

Hughes, R., \& McCarthy, M. (1998). From sentence to discourse: Discourse grammar and English language teaching, Tesol Quarterly, 32(2), 263-287.

Kinnear, P. R., \& Gray, C. D. (2006). SPSS 14 made simple. New York: Psychology Press.

Lai, Y. C. (2009). Language learning strategy use and English proficiency of university freshmen in Taiwan. TESOL Quarterly, 43(2), 255-280.

Lakoff, G., \& Johnson, M. (1981). Conceptual metaphor in everyday language. In M. Johnson (Ed.), Philosophical perspectives on metaphor (pp. 286-325). Minneapolis, MN: University of Minnesota Press.

Langacker, R. W. (2000). Grammar and conceptualization. Berlin \& New York: Mouton de Gruyter.

Langacker, R. W. (2001). Cognitive linguistics, language pedagogy, and the English present tense. In M. Pütz, S. Niemeier \& R. Dirven (Eds.), Applied Cognitive Linguistics I: Theory and Language Acquisition (pp. 3-40), Berlin: Mouton de Gruyter.

Langacker, R. W. (2005). The conceptual basis of grammatical structure [conference handout]. Georgetown University Round Table on Languages and Linguistics Gurt 2005 Retrieved from Cornell University website lrc.cornell.edu/events/past/.../langacker.pdf

Langacker, R.W. (2006). The conceptual basis of grammatical structure. In Byrnes, H., Weger-Guntharp, H. \& Sprang, K. (Eds.). Educating for advanced foreign language capacities: Constructs, curriculum, instruction, assessment, 17-39. Washington, D.D.: Georgetown University Press.

Langacker, R. (2008). Cognitive grammar: A basic introduction. Oxford: Oxford University Press.

Lanham, R. A. (2006). The economics of attention: style and substance in the age of information. Chicago: The University of Chicago Press.

Lee, N., \& Huang, Y. Y. (2004). To be or not to be - the variable use of the verb be in the interlanguage of Hong Kong Chinese Children. RELC Journal 35, 211-228.

Lightbown, P. M., \& Spada, N. (2006). How languages are learned ( $3^{\text {rd }}$ ed.). New York: Oxford University Press.

McCarthy, M. J. (2001). Issues in applied linguistics. Cambridge: Cambridge University Press.

Mitchell, R., \& Myles, F. (1998). Second language learning theories. London: Arnold.

Niemeier, S., \& Reif, M. (2008). Making progress simpler? Applying cognitive grammar to tense-aspect teaching in the German EFL classroom. In S. de Knop, and T. de Rycker (Eds.), Cognitive Approaches to Pedagogical Grammar (pp. 225-255). Berlin: Mouton de Gruyter.

Puchta. (2010, March). Teaching grammar - the fun way. Session presented at the first Istek Schools International 
ELT conference, Istanbul.

Prabhu, N. S. (1995). Concept and conduct in language pedagogy. In G. Cook \& B. Seidlhofer (Eds.), Theory and practice in applied linguistics: Studies in honour of H. G. Widdowson(pp. 57-71). Oxford: Oxford University Press.

Salaberry, R. (2000). The development of past tense morphology in L2 Spanish. Philadelphia: Benjamins.

Scheffler, P. (2009). Rule difficulty and the usefulness of instruction. ELT Journal, 63(1), 5-12. http://dx.doi.org/10.1093/elt/ccn014

Schmitt, N. (2000). Vocabulary in Language Teaching. Cambridge: Cambridge University Press.

Shin, S. J. (2009). Negotiating grammatical choices: Academic language learning by secondary ESL students. System, $37,391-402$.

Skehan, P. (1998). A cognitive approach to language learning. Oxford: Oxford University Press.

Spada, N., \& Lightbown, P. M. (2008). Form-focused Instruction: Isolated or Integrated? TESOL Quarterly, 42(2), 181 - 207. http://dx.doi.org/10.1002/j.1545-7249.2008.tb00115.x

Stubbs, M. (1983). Discourse Analysis: The Sociolinguistic Analysis of Natural Language. Oxford: Basil Blackwell.

Svalberg, A. (1986). Teaching tense and aspect: A systematic approach. ELT Journal, 40(2), 136-145.

Swan, M. (2005). Legislation by hypothesis: The case of task-based instruction. Applied Linguistics, 26(3), 376-40.

Tyler, A., \& Evans, V. (2001). The relation between experience, conceptual structure and meaning: non-temporal uses of tense and language teaching. In M. Pütz, S. Niemeier \& R. Dirven (Eds.), Applied Cognitive Linguistics I: Theory and Language Acquisition (pp. 63-105), Berlin: Mouton de Gruyter.

VanPatten, B. (2004). Input and output in establishing form-meaning connections. In B. VanPatten, J. Williams, S. Rott \& M. Overstreet (Eds.), Form-meaning connections in second language acquisition (pp. 29-47). Mahwah, NJ: Lawrence Erlbaum Associates.

VanPatten, B., Williams, J., \& Rott, S. (2004). Form-meaning connections in second language acquisition. In B. VanPatten, J. Williams, S. Rott \& M. Overstreet (Eds.), Form-meaning connections in second language acquisition (pp. 1-26). Mahwah, NJ: Lawrence Erlbaum Associates.

Villamil, O. S., \& de Guerrero, M. C. M. (2005). Constructing theoretical notions of L2 writing through metaphor conceptualization. In N. Bartels (Ed.), Applied linguistics and language teacher education (pp. 79-90). New York: Springer.

Yang, S., Huang, Y. Y., \& Lee, N. (2000). Some reflections on English textbook input for Hong Kong students based on a case study of tense-aspect acquisition problems. Asia Pacific Journal of Language in Education, 3(1), $1-24$.

\section{Appendix A}

First, it was underlined that time is universal (concepts of past and present), that is, the linguistic codification of the time frames can differ in different languages. It was also emphasized that the grammatical forms (verbal morphology in tense-aspect marking) are supposed to are only tools use of which should be connected with the meanings/aims/focus of the speakers involved. It was best to focus on the universal concepts and relate these directly to the codifications of the English tense-aspect system. The students were informed of the inefficiency of the rote learning technique and the need for ways to use meaning as a basis to store information regarding the rules. Therefore, a numerical system was introduced as a universal tool to codify the univresal time concepts of present and past.

Then a new distinction was introduced: the verbs were divided under two general categories: be verbs and other verbs. In fact, other verbs were categorized as neology of $d$ verbs, benefiting from the $b$ and $d$ shown to serve the distinction as the reverse images of one another. The researcher/teacher drew analogy between the numerical codification introduced and the alphabetic codes (first letters in the former category - be auxiliaries). It was underlined that the alphabetical codes of A and I associate number one (the first letter in the Latin alphabet, the roman numeral I, the A used for the notions of number one or first quality). It was told that "be" verbs are important as a key to the passive voice and the progressible aspect as well as the copula for the simple aspect. 
In the case of other verbs ( $\mathrm{d}$ verbs), distribution was the key as a numerical codification (one $\mathrm{d}$ in do/does, double $\mathrm{d}$ in did) the auxiliaries for the other verbs in case of interrogative, negative and emphatic statements. In fact, it was stated that even the first letters of the word distribution was used in order to reinforce distinction. In case of positive statements where do or did as auxiliaries are not used, the students were demonstrated that learners can complement the lack of symmetry with the assumption embedded in the "d" verbs (other verbs distinct from "be" auxiliaries). The analogy was drawn between verbs other than "be" auxiliaries and the neology "d" resembling/linking it to the first "d" of "did" and the past tense marker "-ed" to the second "d".

It was important that present perfect tense be excluded from the first lessons and presented subsequently having taught the present simple/progressive and past simple/progressive tenses. This tense is nonexistant in Turkish language, codified with different system of forms (e.g. contextual clues). Apart from codification differences, the students were informed that it is the perceptions/focus/proirity/intention that he/she wants to communicate/express that matter in the selection of the aspect. In order to protect students from ambiguities regarding the way they will be tested, they were reassured of such clues as adverbials of time triangulated with L1 translations and, if neccessary, extra clues presented in parantheses). For efficiency, teaching included both presentation and discovery techniques. The students were also encouraged to use the metalanguage and maket he most of the simplication it is assumed to bring. The frequency of exercises/practice was raised due to practical use of numerical/visual codification instead of lengthy and complex rule explanations, technical terms or possible L1 interferences.

\section{Appendix B}

Name Surname: $\quad$ Department:

DID, WAS, IS, WERE, DO, HAS, AM, ARE, HAVE, DOES, BEEN, -ED, -S, - ING

Her niece ------------ (olumsuz, interfere) when Leyla ------------ (speak). (Leyla konuştuğunda yeğeni araya girmez.)

You ----------- (be) (try) to catch up with your rival since last season. (Geçen sezondan beri rakibini yakalamaya çalı̧̧ıorsun.)

Yavuz ----------- (begin/began/begun) the assignment 3 days ago. (begin, began, begun) (Yavuz, üç gün önce göreve başladi.)

Her boyfriend ------------ (olumsuz, give/gave/given) her enough affection yesterday evening. (Erkek arkadaşı geçen Cumartesi ona yeterli sevgi vermedi.)

She -------- (be) (negotiate) with me and my colleague here half an hour ago. (O (bayan) yarım saat önce burada benimle ve meslektaşımla müzakere ediyordu.)

Burak's relatives ----------- (be) (fund) my university fees for the last 3 terms. (Burak'ın akrabaları son üç dönemdir benim üniversite harçlarımı karşılıyorlar.)

My patient ---------- (olumsuz, take/took/taken) his medication for the last two months.

(Hastam son iki aydır ilacını almadı.)

Her husband and I ----------- (be) experts on Europe but they ----------- (olumsuz, understand) our expertise. (Eşi ve ben Avrupa konusunda uzmanız ama uzmanlığımızı anlamazlar.)

A few buses ----------- (depart) from Kırklareli yesterday morning but our plane (take/took/taken) off at 6:00 yesterday evening. (Birkaç otobüs Kırklareli'nden dün sabah ayrıldı ama uçağımız dün akşam kalkmadı.) 
His grandson (olumsuz, be) (have) fun with her granddad at the moment. (Torunu dedesiyle şu anda iyi vakit geçirmiyor.)

My boss and I (do/did/done) our best until now, for all those years. (Bütün bu yıllar boyunca -şimdiye kadar- patronum ve ben elimizden geleni yaptık.)

Sezai and his wife ----------- (go: gitmek; go/went/gone) to a skiing center every winter. (Sezgin ve hanımı her kış bir kış merkezine gider.)

Our athletes (be) stronger last year but we (olumsuz, do) our best to motivate them. (Atletlerimiz geçen yıl daha kuvvetliydi fakat biz onları motive etmek için elimizden geleni yapmadık.)

You ---------- (do/did/done) everything to continue to work in Istanbul because your daughter (be) there. (İstanbul'da çalışmaya devam etmek için her şeyi yaparsın çünkü kızın orada.)

One of our forward players ------------ (be) too weak against their defence players last weekend.

(Bizim forvet oyuncularımızdan biri geçen hafta sonu onların savunma oyuncularına karşı çok zayıftı.)

My sisters ----------- (watch) "Buzda Dans” on TV every Sunday night. (Kız kardeşlerim hergün televizyonda Buzda dans1 seyreder.)

I ------------ (olumsuz, be) your fan. (Ben sizin hayranınız değilim.)

Their president ----------- (be) in office for the last four years. (Onların başkanı son dört senedir görevinin başında.)

When we ---------- (arrive) home last Sunday, my cousins' friends ----------- (be) (watch) my documentaries.

(Geçen Pazar eve vardığımızda, kuzenlerimin arkadaşları belgesellerimi izliyorlardı.)

\section{Appendix C}

$\left(\mathrm{F}_{(1,38)}=18.250, p<.05\right)\left(\right.$ See Table 2.); $\left(\mathrm{F}_{(1,54)}=77.327, p<.05\right)($ See Table 4.)

Table C1: Experiment 1 (year 1): Test Performance (Means and Standard Deviations) of Students in the Departments of Chemistry Teaching (experimental method) and Geography Teaching (Traditional method)

\begin{tabular}{llccc}
\hline \multirow{2}{*}{ Method } & & $\underline{\mathrm{N}}$ & Mean $($ Max $=25)$ & Standard deviation \\
\hline Pretest & Experimental tense model & 20 & .35 & 1.14 \\
& Traditional method & 20 & 7.15 & 5.63 \\
Posttest & Experimental tense model & 20 & 6.50 & 4.99 \\
& Traditional method & 20 & 7.75 & 7.45 \\
& & & & \\
\hline
\end{tabular}


Table C2: ANOVA Results Students in the Departments of Chemistry Teaching and Geography Teaching

\begin{tabular}{llllll}
\hline Source of variance & SS & df & MS & F & P \\
\hline Between groups & 2159.185 & 39 & & & \\
(Group) Experimental tense model / Traditional & 324.01 & 1 & 324.01 & 6.709 & $p=.014$ \\
Error & 1835.175 & 38 & 48.294 & & \\
Within groups & 702.5 & 40 & & & \\
(Measure) Pretest - Posttest & 227.812 & 1 & 227.812 & 26.996 & $p=.000$ \\
Group * Measure & 154.013 & 1 & 154.013 & 18.250 & $p=.000$ \\
Error & 320.675 & 38 & 8.439 & & \\
Total & 2861.685 & 79 & & & \\
\hline
\end{tabular}

Table C3: Experiment 2 (year 2): Test Performance (Means and Standard Deviations) of Students in the Departments of Art Teaching (experimental method) and Religion Teaching (Traditional method)

\begin{tabular}{llccc}
\hline Method & & $\mathrm{N}$ & Mean $(\mathrm{Max}=25)$ & Std deviation \\
\hline Pretest & Experimental tense model & 33 & 5.42 & 6.09 \\
& Traditional method & 23 & 4.48 & 5.48 \\
Posttest & Experimental tense model & 33 & 18.33 & 5.86 \\
& Traditional method & 23 & 7.09 & 6.36 \\
\hline
\end{tabular}

Table C4: ANOVA Results for the First Year Students of the Art Teaching and Religion Teaching Departments, Atatürk University in the $2^{\text {nd }}$ Year Experiment

\begin{tabular}{lccccc}
\hline Source of variance & $\mathrm{Ss}$ & $\mathrm{df}$ & $\mathrm{ms}$ & $\mathrm{f}$ & $\mathrm{p}$ \\
\hline Between groups & 4342.25 & 55 & & & \\
(Group) Experimental tense model/Traditional & 1007.394 & 1 & 1007.394 & 16.312 & $\mathrm{P}=.000$ \\
Error & 3334.856 & 54 & 61.757 & & \\
Within groups & 2852.969 & 56 & & & \\
(Measure) Pretest - Posttest & 1631.862 & 1 & 1631.862 & 175,503 & $\mathrm{P}=.000$ \\
Group * Measure & 719,004 & 1 & 719.004 & 77.327 & $\mathrm{P}=.000$ \\
Error & 502.103 & 54 & 9.298 & & \\
Total & 7195.219 & 111 & & & \\
\hline
\end{tabular}

